
\title{
$\left.\mathbf{C}^{-}\right\rceil$CONGRESO
INTERNACIONAL \\ SOBRE \\ LF_O FOTOGRAFÍA
}

Congreso Internacional sobre Fotografía

UPV, 5 y 6 octubre 2017

Doi: http://dx.doi.org/10.4995/CIFo17.2017.6716

ISBN: 978-84-9048-604-7

\section{Un álbum de recuerdos prestados: La fotografía de Google Street View como vestigio de pertenencia en la experiencia del desplazamiento migratorio ${ }^{1}$}

\author{
Anna Borisova ${ }^{a}$ y Lorena Amorós Blascob \\ a Investigadora predoctoral en la Universidad de Murcia, Departamento de Bellas Artes, anna.borisova@um.es \\ b Profesora TUI de la Universidad de Murcia, Departamento de Bellas Artes, lorenamo@um.es
}

\begin{abstract}
The present paper offers a reflection on the potential of the platform GOOGLE STREET VIEW as a tool of artistic mediation with the immigrant community. We disigned a workshop that proposes to make a virtual trip to the native land of the participants through this immense $3 D$ photographic archive, creating an album of "borrowed memories" with images of significant landscapes for them. The change of the country of residence not only exposes the person to a different culture, it also deprives him of contact with places that keep memories of the events of his past. The intimate relationship between memory, identity and landscape, gives the images that portray these spaces a powerful emotional load, allowing the immigrant to tell their story from the stages of their past performance. In this sense, the activity we propose gives the opportunity to participants to recall their place of origin through the photographic landscape with the goal of restoring the continuity of their narrative identity, interrupted by the experience of displacement. Likewise, presenting the visual story to the companions allows sharing the mourning of uprooting, building new affective ties with the host environment.
\end{abstract}

Keywords: Immigration, acculturation, memory, Google Street View's landscapes, artistic mediation.

\begin{abstract}
Resumen
La presente comunicación ofrece una reflexión sobre el potencial de la plataforma GOOGLE STREET VIEW como herramienta de mediación artística dirigida al colectivo inmigrante. Desarrollamos una propuesta de taller que plantea realizar un viaje virtual a la tierra natal de los participantes a través de este inmenso archivo fotográfico $3 D$, creando un álbum de "recuerdos prestados" con las imágenes de los paisajes significativos para ellos. El cambio del país de residencia no sólo expone a la persona a una cultura diferente, también la priva del contacto con los lugares que guardan recuerdos de los acontecimientos de su pasado. La relación
\end{abstract}

\footnotetext{
1 Esta investigación fue financiada por el Ministerio de Economía y Competitividad en el marco de los proyectos I+D con referencias HAR2015-66288-C4-4-P y HAR2015-64106-P. Asimismo fue realizado bajo el amparo del contrato FPU del Plan Propio de la Universidad de Murcia.
} 
Un álbum de recuerdos prestados: La fotografia de Google Street View como vestigio de pertenencia en la experiencia del desplazamiento migratorio

intima entre la memoria, la identidad y el paisaje, dota a las imágenes que retratan estos espacios de una carga emocional muy potente, permitiendo al inmigrante contar su historia a partir de los escenarios de su actuación pasada. En este sentido, la actividad que proponemos da oportunidad a los participantes de rememorar su lugar de origen a través del paisaje fotográfico, restableciendo asi la continuidad de su narrativa identitaria, interrumpida por la experiencia del desplazamiento. Asimismo, presentar el relato visual ante los compañeros permite compartir el duelo del desarraigo, construyendo nuevos lazos afectivos con el entorno de acogida.

Palabras clave: Inmigración, aculturación, memoria, paisajes Google Street View, mediación artística.

\section{Introducción}

Hoy en día vivimos en un mundo globalizado cuya estructura social interna se ve afectada por los continuos desplazamientos entre diversos territorios. Las diferencias en la situación socio-económica de diversos países, la envergadura de los conflictos bélicos actuales junto con el desarrollo de la tecnología de comunicación que facilita el acceso a la información sobre posibles opciones vitales, aumentan la movilidad de la población mundial. Como el resultado millones de personas se ven involucrados en los procesos de desplazamiento. En el presente texto reflexionamos en torno a la problemática de la identidad migratoria presentando el paisaje como un importante factor de la construcción del "yo". Asimismo, pretendemos poner de relieve el rol de la memoria personal como posible base estabilizadora en el proceso de la aculturación. En este sentido, cobran valor las fotografías de paisajes que muestran escenarios de los acontecimientos importantes en la vida del inmigrante, sin embargo, este tipo de imágenes rara vez forman parte de nuestro archivo familiar.

Por otro lado, el desarrollo tecnológico pone a nuestro alcance nuevas soluciones a las problemáticas que surgen como el resultado de los cambios globales. Así, la plataforma virtual GOOGLE STREET VIEW fue creada en 2007 como parte de GOOGLE MAPS para proporcionar a sus usuarios la información adicional necesaria para orientarse en un espacio concreto, conformando un archivo visual de gran parte de las vías transitables del planeta. Asimismo, este repositorio fotográfico de paisajes en $3 \mathrm{D}$, proporciona al inmigrante la posibilidad única de viajar en el tiempo y el espacio, visitando y haciendo fotos mediante captura de pantalla de los lugares que se presentan como vestigios de su lugar de origen. De modo que crear un relato visual compuesto por las fotografías de GOOGLE STREET VIEW, reinventando así la idea del álbum familiar, permite reconstruir la narrativa subjetiva a partir de estas imágenes vinculadas al espacio y a una persona en concreto.

Por consiguiente, nuestra hipótesis trata de demostrar cómo la plataforma GOOGLE STREET VIEW puede servir como herramienta para la mediación artística con el colectivo inmigrante. Para ello, primeramente haremos un estudio interdisciplinar en torno a los conceptos-clave para la investigación: la identidad migratoria, el territorio, el paisaje, la memoria, la integración. El análisis de las cuestiones mencionadas se lleva a cabo teniendo en cuenta los planteamientos propios de diversas áreas de conocimiento: el arte, la sociología, la psicología, la filosofía y la antropología, expresados en la bibliografía temática. Por otro lado, exploraremos las posibilidades que ofrece la plataforma virtual GOOGLE STREET VIEW como fuente de inspiración artística o herramienta de intervención psicosocial. Seguidamente, en base a la reflexión teórica, esbozaremos una propuesta de taller, cuya metodología se basa en las premisas marcadas en el estudio de Ascensión Moreno González (2010) sobre la mediación artística para la inclusión social. En esta propuesta, por medio de la apropiación de las imágenes (captura de pantalla durante el viaje virtual), los participantes de la actividad tendrán la oportunidad de crear una especie de álbum de "recuerdos prestados", una recopilación de los paisajes 
de su tierra natal que componen un posible relato sobre su vida pasada. Seguidamente, las narrativas obtenidas se pondrían en común para llevar a cabo una reflexión grupal en torno a esta experiencia.

\section{Objetivos}

A continuación, los objetivos que nos marcamos en esta investigación son los siguientes:

- Establecer relaciones entre los conceptos de identidad, memoria, territorio y paisaje en el marco de la experiencia del desplazamiento migratorio.

- Demostrar cómo los lazos afectivos vinculados a un lugar y su representación fotográfica son importantes para la construcción identitaria del inmigrante.

- Poner de relieve el rol de la fotografía rememorativa como agente estabilizador de la identidad en el proceso de la aculturación.

- Explorar el potencial de la aplicación GOOGLE STREET VIEW como herramienta para la mediación artística dirigida al colectivo inmigrante.

-Esbozar una propuesta de taller con el uso de plataforma virtual GOOGLE STREET VIEW en base al estudio realizado.

\section{Desarrollo de innovación}

\subsection{Aplicación GOOGLE STREET VIEW}

Desde el año 2007 GOOGLE ofrece a sus usuarios un nuevo software complementario a la aplicación GOOGLE MAPS. El proyecto denominado GOOGLE STREET VIEW consiste en la creación de un archivo visual de las vías abiertas al tránsito de un coche de todo el planeta. Para realizar esta tarea, la empresa envía miles de automóviles eléctricos híbridos equipados con una cámara de nueve objetivos capaz de capturar imágenes a $360^{\circ}$. Cada diez o veinte metros, el aparato realiza una toma fotográfica de manera automática. Posteriormente, un programa informático se encarga de unir las imágenes y crear la ilusión de la tridimensionalidad que vemos en la pantalla. Además, con el fin de evitar problemas legales, la aplicación difumina los rostros de las personas y las matrículas de los coches que entran casualmente en el encuadre de la cámara.

Es importante mencionar que hoy en día GOOGLE no ha conseguido aún llegar a todos los rincones del mundo debido a las barreras legales que ponen algunos de los países para evitar el registro fotográfico de sus calles. Sin embargo, las negociaciones parecen avanzar de manera favorable y cada vez más estados se unen al proyecto.

La finalidad del entorno GOOGLE STREET VIEW es ofrecer una experiencia más completa a los usuarios de GOOGLE MAPS, proporcionando información más detallada para poder orientarse en el espacio. Sin embargo, este enorme repositorio fotográfico tiene muchas otras utilidades, sobre todo si nos centramos en el ámbito artístico. Muchos artistas, entre los que podemos destacar Jon Rafman (9-eyes, 2009-hoy), Paolo Cirio (Street Ghosts, 2012) y Joachim Schmid (26 Gasoline Stations, 2009), se han interesado por esta plataforma informática, viéndola como una fuente inabarcable de inspiración creativa.

Paolo Cirio en su proyecto Street Ghosts (2012) ofrece una reinterpretación del arte urbano presentando las nuevas tecnologías como un factor clave en la transformación de nuestra realidad. El artista busca a través de GOOGLE STREET VIEW las paredes de las ciudades en las que se permiten realizar graffitis y, si aparecen personas retratadas eventualmente en estos lugares, captura la imagen. Su propuesta consiste en imprimir estos retratos fortuitos a tamaño real de la figura humana que representan y colocar las fotografías obtenidas en los 
Un álbum de recuerdos prestados: La fotografia de Google Street View como vestigio de pertenencia en la experiencia del desplazamiento migratorio

lugares físicos oportunos (las paredes de los edificios que sirvieron de fondo para la imagen ofrecida por GOOGLE) (Katz, 2012). De esta manera, se vincula el espacio público real con el virtual que a menudo tiene más peso en nuestras experiencias debido a nuestro estilo de vida en la actualidad.

Por su parte, Joachim Schmid con el material visual obtenido a través de la aplicación GOOGLE STREET VIEW creó un proyecto fotográfico titulado 26 Gasoline Stations (2009), haciendo referencia al primer libro de artista realizado por Ed Ruscha con el fin de adaptar esta idea a la específica de la era digital.

Quizá, el artista que más fama ha obtenido gracias al proyecto relacionado con el entorno STREET VIEW es Jon Rafman. Desde el año 2009, este artista canadiense viaja virtualmente en búsqueda de "poemas visuales" (Cuéllar, 2010) captados por la cámara del coche GOOGLE buscando el momento fugaz y único. A través de este medio, Rafman ha realizado varias series de fotografía, siempre manteniendo la estética característica del software, incluido el rótulo de copyright de GOOGLE (Walker, 2012). El artista incide en que las imágenes ofrecidas por el programa conforman un ejemplo perfecto de neutralidad e imparcialidad. Como él mismo afirma: "registran los acontecimientos de forma azarosa construyendo el relato de la vida humana" (Rafman, 2009). Además, estas fotos son públicas, carentes de la autoría explícita, lo que las convierte en propiedad "de todos y de nadie a la vez" (Lathrop, 2013). De esta manera, Rafman en su obra cuestiona el sentido mismo de las imágenes capturadas por GOOGLE como un nuevo modo de documentar el entorno en contraposición a la percepción humana de la realidad circundante (Rafman, 2009). Haciendo estas selecciones, el artista atribuye nuevos significados a la imagen imparcial de la cámara automática reflejando la experiencia contemporánea de forma crítica. En este sentido, Rafman acepta como un hecho consumado la hegemonía de GOOGLE a la hora de enmarcar nuestras experiencias y conocimientos (Rafman, 2009). No obstante, se presenta como el artistacurador que elige las obras dignas de ser mostradas reafirmándose en la importancia de la mirada humana frente a la frialdad de la tecnología.

Como hemos podido observar a través de los proyectos de los artistas referenciados, la utilización de la aplicación STREET VIEW de GOOGLE ofrece infinidad de posibilidades para la expresión artística. Los proyectos fotográficos mencionados plantean una reflexión en torno a la permeabilidad de los límites entre lo público y lo privado, provocada por los cambios en los modos de percibir el mundo en el marco de la sociedad del espectáculo. Por otro lado, todos ellos de un modo u otro aluden a la noción del paisaje como marco de la experiencia identitaria.

\subsection{Territorio, paisaje e identidad migratoria.}

Es importante remarcar que los conceptos de "paisaje" e "identidad" se presentan en nuestro estudio como constructos socioculturales y, por tanto, debemos entenderlos como categorías sujetas a una transformación continua. En este sentido, el territorio constituye parte del contexto en que se desarrolla la subjetividad del individuo ofreciéndole un referente de identificación simbólica (Valera, 1997; Zapiain, 2011). A su vez, el paisaje es la percepción vivencial del territorio (Giménez, 2001), la apreciación que depende de las experiencias vinculadas al mismo (Muñoz y Crespo, 2014). Como tal, este concepto hace referencia a una realidad que tiene matices tanto objetivos, como subjetivos y, por tanto, actúa de enlace estableciendo una relación con la dimensión personal y social de la identidad (Valera, 1997; Zapiain, 2011). Un individuo realiza apreciaciones del territorio que habita siguiendo los criterios constituidos socialmente, pero pasando la información obtenida por el filtro de la experiencia personal. En esta experiencia, los afectos y los sentimientos cotidianos pasan a formar parte de nuestros criterios de autodefinición como sujeto (Zapiain, 2011). De esta manera, el paisaje ejerce influencia en la construcción de la subjetividad individual y colectiva determinando las formas de interpretar la realidad y relacionarnos con los demás. Es tanto así, que Mónica Muñoz Montejano y María José Crespo Sierra (2014) afirman que "el nivel al que se encuentran los lugares y espacios de la vida cotidiana en relación a la formación de la identidad, son equiparables al de los individuos con los que la persona se 
relaciona" (p. 16). Cabe preguntarse entonces, qué efecto tendría sobre el individuo la privación total de los paisajes que forman parte de su memoria pasada. Sobre este asunto, existen numerosos estudios que describen consecuencias psicológicas derivadas del cambio cultural drástico tras el desplazamiento migratorio.

En el libro La persona más allá de la migración, Luisa Melero Valdés describe como las incongruencias en la autodefinición pueden afectar al individuo en este caso:

[...] la situación social de la persona migrante, y su propia identidad, vienen marcadas por su condición de sujeto fronterizo entre dos mundos, entre dos sociedades. La condición de inmigrante sitúa al individuo en una situación ciertamente inestable en cuanto a la propia identidad se refiere: ni ciudadano, ni extranjero, ni totalmente al lado de uno mismo, ni totalmente al lado del otro, el inmigrante se sitúa en la frontera del ser y el no-ser social (Melero, 2010, p.135).

Un inmigrante está cuestionando continuamente su identidad y, por tanto, se ve obligado a poner en marcha una serie de estrategias de adaptación a su nueva situación. El modelo de la aculturación desarrollado por John W. Berry ofrece un análisis profundo de la respuesta psicológica del individuo ante las exigencias de un contexto cultural diferente. Su teoría se enmarca dentro de la Psicología Transcultural, el área científica que estudia el conjunto de las modificaciones de subjetividad que se producen en el curso del intercambio cultural. La versión definitiva del modelo presentada en 1997 distingue cuatro estrategias identitarias desde la perspectiva de la población inmigrante: asimilación, marginación, separación e integración. Las tres primeras describen las actitudes de rechazo, ya sea hacia la cultura de acogida en caso de la separación, a la de origen (la asimilación) o a ambas (la marginación), en todo caso dificultando la adaptación. La integración, en cambio, supone la creación de un consenso entre las costumbres propias y la cultura de acogida asimilando lo mejor de las dos (Melero, 2010) y permitiendo así preservar las ventajas de ambos espacios simbólicos que integran la identidad de la persona desplazada. De esta manera, en la teoría de Berry esta actitud se postula como la estrategia más efectiva (Melero, 2010). En el proceso de integración el mayor desafío consiste en conseguir mantener el equilibrio entre el pasado y el presente para preservar la sensación de la continuidad del propio ser sin perjudicar el proceso de la adaptación. En este sentido, la memoria personal adquiere un gran valor como "anclaje" seguro para la edificación de la subjetividad (Revilla, 2003). Según Juan Carlos Revilla: "el trabajo principal de gestión de la identidad personal consiste en convertir todo ese material proveniente de la experiencia en narraciones sobre uno mismo" (2003, p.61). Este relato resulta imprescindible para sentir la coherencia del propio ser y, como afirma este autor, "por eso mismo, la memoria nos sujeta a nuestra biografía, a nuestra historia, a nuestra identidad, haciendo impensable la disolución de la identidad del sujeto memoriado" (Revilla, 2003, p.62). Aquí, la reflexión de Revilla se conecta con la teoría de la subjetividad narrativa de Paul Ricoeur (1996).

\subsection{La memoria identitaria y el paisaje fotográfico. Un álbum de "recuerdos prestados"}

Con el fin de reestablecer la continuidad del "yo" interrumpida por la experiencia del desplazamiento, el inmigrante necesita reconstruir su narrativa identitaria en base a los recuerdos del pasado. En este sentido, un álbum familiar o un diario personal, en calidad de archivos de memoria, ofrecen material adecuado para iniciar la tarea. En efecto, los relatos, los objetos y las imágenes que guardan relación con las experiencias anteriores al cambio del lugar de la residencia se convierten en un colchón de la seguridad identitaria, a través de los testimonios que prueban y verifican la historia personal. La fotografía configura una parte fundamental de este proceso rememorativo, ya que supuestamente dan muestra del contacto directo de un sujeto con el pasado. 
Un álbum de recuerdos prestados: La fotografia de Google Street View como vestigio de pertenencia en la experiencia del desplazamiento migratorio

Al hilo de ello, Don Slater (1997) en su ensayo La fotografía doméstica y la cultura digital afirma que:

La metáfora del "álbum familiar", no importa que forma física tome, significa un proceso de edición de imágenes en símbolos y líneas narrativas mediante las cuales se constituye y establece la identidad familiar. El realismo de las fotografías como muestras del pasado parece afianzar una identidad construida en el flujo natural del tiempo. (Slater, 1997, p. 184)

Don Slater (1997) señala aquí al término "identidad familiar" en relación al "yo" colectivo de un grupo social establecido en función del parentesco, y afirma que las fotografías rememorativas pertenecientes a este grupo conforman una narrativa que funde las subjetividades individual y colectiva en un todo. En efecto, los ritos, costumbres, conocimientos y convenciones transferidos de una generación a la otra en el marco de una familia crean un particular marco afectivo. A su vez, este autor menciona como uno de los modos de trasmitir el legado familiar, el rito de "lectura" de un álbum fotográfico, cuya visualización va acompañada de un relato pormenorizado de cada acontecimiento representado (Slater, 1997). En este sentido, se evidencia la envergadura del conflicto identitario que experimenta una persona al perder el contacto directo con su familia tras inmigrar a otro país. Los lazos afectivos mantenidos durante años se debilitan interrumpiendo la continuidad de la historia familiar. Esto deja un vacío enorme tanto en la subjetividad colectiva del grupo, como en el "yo" del propio inmigrante.

Por otro lado, es importante remarcar que las imágenes recogidas en un álbum familiar no tienen carácter totalmente documental u objetivo. Marcela Lockett Destri (2014) hace alusión tanto a la capacidad de la imagen fotográfica de evocar un recuerdo real, como a la posibilidad de construir un significado nuevo de la situación retratada en base a las vivencias actuales:

Cada fotografía que una persona toma es también una forma de autorretrato, una especie de "espejo con memoria" que refleja aquellos momentos que fueron suficientemente especiales para ser congelados en el tiempo para siempre. [...] al observar una fotografía, las personas crean significado que ellos creen está proviniendo de la foto misma y este significado puede o no ser el que el fotógrafo originariamente intentó expresar. Entonces el mensaje emocional depende de quién está mirando. Porque las percepciones y experiencias de vida encuadran y definen lo que se ve como real (Weiser, citado en Lockett, 2014, pp. 229-230).

Por consiguiente, el álbum familiar se conforma teniendo en mente el valor sentimental de los recuerdos y, como tal, tiende a idealizar los momentos memorables y huir de lo cotidiano y lo banal. A su vez, las convenciones que determinan cuál de los acontecimientos debe ser registrado fotográficamente y cómo, se forman en el marco social más amplio, creando un vínculo entre el grupo familiar y la cultura de la sociedad a la que pertenece. En este sentido, el desplazamiento del centro identitario del inmigrante provocado por el cambio del entorno cultural afecta también su apreciación del valor sentimental de los objetos de recuerdo. Junto con los retratos de los seres queridos adquieren gran importancia las imágenes que representan los paisajes conocidos como vestigios y testimonio del origen de procedencia. Sin embargo, los álbumes convencionales no suelen acoger este tipo de fotografías. En el mejor de los casos el paisaje sirve de fondo para una escena familiar retratada.

En este sentido, la plataforma GOOGLE STREET VIEW ofrece una solución al problema planteado, ya que permite realizar un viaje virtual a cualquier parte del mundo donde pasaron los automóviles GOOGLE. Para un inmigrante representa la oportunidad única de visitar su tierra y volver a conectar con sus orígenes sin tener que desplazarse.

A pesar de la fría objetividad de las imágenes que componen el archivo del programa, el sentido de las mismas se transforma cuando se relacionan con las vivencias concretas de una persona y, de esta manera, se convierten 
en el soporte de su memoria (Lockett, 2014). El valor sentimental de determinados paisajes fotográficos aumenta para una persona desvinculada de su pasado cultural (Proshansky, citado en Zapiain, 2011). La relación que se establece entre la memoria y el paisaje, dota a las imágenes que reflejan estos espacios significativos de una carga emocional muy potente (Nogué, 2015). El paisaje, así, se postula como el soporte privilegiado de la subjetividad (Zapiain, 2011), como un componente fundamental de la narrativa identitaria de la persona que evoca el sentido de pertenencia. Por consiguiente, componer un álbum de los paisajes "familiares" a partir de un viaje virtual por medio de GOOGLE STREET VIEW constituye para un inmigrante un acto significativo, comparable con repasar su historia personal a partir de las fotografías pertenecientes a su familia (Muñoz y Crespo, 2014). Esta afirmación nos hace pensar en las posibles aplicaciones prácticas de este archivo fotográfico en el marco de una intervención de mediación artística con un grupo de personas que han tenido que pasar por la experiencia del desplazamiento.

\section{Propuesta de una actividad en base a la metodología de mediación artística dirigida al colectivo inmigrante}

Ascensión Moreno González (2010) habla de mediación artística refiriéndose no sólo a los procesos dirigidos a promover la inclusión social, sino también a las herramientas que se sitúan en el límite entre la educación artística y la arteterapia, describiendo una metodología de intervención. En este sentido subraya los beneficios del proceso creativo para el desarrollo integral de la persona, afirmando que puede tener un efecto terapéutico. Por tanto, el objeto de la creación se presenta como mediador en la experiencia del sujeto y, como tal, puede impulsar la transformación personal. Por otro lado, una parte fundamental de la mediación artística la constituye el proceso de reflexión inmediatamente posterior a la intervención que permite interiorizar los cambios surgidos durante la misma. En un debate grupal dirigido por el mediador o la mediadora, los participantes intercambian sus impresiones sobre lo ocurrido durante la sesión, sus pensamientos y sus sentimientos en el curso de la misma y, de esta manera, se hacen conscientes del alcance de la experiencia vivida y su repercusión a nivel personal. Por consiguiente, usando la estructura de talleres de arteterapia como referente metodológico, Moreno (2010) aconseja realizar los talleres de mediación en grupos pequeños, y con sesiones que duren al menos dos horas para poder incorporar tanto la creación como la reflexión en la actividad que se promueva. Sin embargo, en el caso que nos ocupa, a diferencia de las intervenciones arteterapéuticas, el artista, el educador, el monitor o el trabajador social (o un equipo compuesto por varios especialistas) que coordina la actividad adopta el papel de guía, absteniéndose de dirigir su desarrollo o de proponer juicios de valor sobre el proceso o los resultados. Su objetivo es facilitar un entorno seguro y agradable para los participantes.

La metodología de la mediación artística alude al proceso creativo como vía de expresión alternativa a la comunicación verbal, que da oportunidad de entrar en conexión con las emociones que, por diversas circunstancias, uno trata de bloquear. En la propuesta que vamos a proponer, trataremos que las personas que formen el grupo restablezcan su vínculo con el pasado a través del relato visual permitiendo avanzar en el proceso de adaptación si el inmigrante decide optar por la estrategia de integración.

En este sentido, en el estudio de Víctor Yanes Córdoba (2007) titulado La narrativa visual como metodología del sentido: articulación metodológica e implicaciones terapéutico-educativas se clarifica la importancia de la construcción del sentido a través del relato visual:

A través de un proceso de distanciación (o mediación) simbólica, la narrativa visual nos ayuda a contemplar nuestras propias vidas a la luz de nuevas perspectivas, otorgándonos un punto de comparación para reflexionar críticamente sobre nuestras propias condiciones de vida. [...] La construcción de sentido adquiere importancia operativa en la vida de las personas, como sujetos colectivos, porque además de construir el conocimiento, les ayuda a definir el rumbo de sus vidas, a 
Un álbum de recuerdos prestados: La fotografía de Google Street View como vestigio de pertenencia en la experiencia del desplazamiento migratorio

tomar decisiones, a buscar alternativas en la solución de problemas, a explicar lo que acontece, así como lo que afecta a las personas y ayuda a integrar a las personas a la vida social (Yanes, 2007, pp. 237-238).

El autor insiste en la incorporación a las metodologías relacionadas con las narrativas visuales de "procesos que tienen que ver con el desarrollo del educando como sujeto social y con la construcción de habilidades personales vinculadas a la realidad personal y social en sus diferentes niveles y ámbitos, que integren las experiencias visuales del educando con sus narrativas y construcciones como sujetos" (Yanes, 2007, p. 238).

Por consiguiente, hemos desarrollado el diseño del taller de mediación artística siguiendo las premisas metodológicas del estudio de Moreno (2010) y Yanes (2007).

La propuesta de taller que lanzamos consiste en una actividad que duraría 3 sesiones de 2 horas cada una. El grupo de trabajo no debería superar 10 personas, siendo 5 un número óptimo de participantes. El espacio en el que se desarrollaría el taller debería estar equipado con ordenadores con acceso a Internet y un programa básico de edición de vídeo, como KDENLIVE, por ejemplo, para cada participante. Asimismo, el espacio debería disponer de una pantalla y un proyector de vídeo para la presentación de los trabajos finales.

En la primera sesión nos encargaríamos de generar un ambiente empático entre los miembros del grupo para poder trabajar en un entorno agradable y dinámico. Para ello resulta fundamental dedicar el tiempo necesario para las presentaciones entre los participantes. Seguidamente se explicarían los objetivos y los procedimientos del taller, adaptando el discurso al nivel de dominio de la lengua castellana que presentan los miembros del grupo. Sobre esta cuestión, si fuera necesario, se ofrecería una atención personalizada. A continuación introduciríamos las posibilidades que ofrece la aplicación GOOGLE STREET VIEW y haríamos un paseo de prueba por una calle cercana al espacio de trabajo. Como durante el taller las fotografías se realizarían por medio de la captura de pantalla, sería importante explicar el procedimiento a realizar, creando en cada equipo informático una carpeta para almacenar las imágenes obtenidas. A continuación, se animaría a los participantes a viajar virtualmente a su tierra natal para componer su álbum de "recuerdos prestados", recopilando las fotografías de los paisajes significativos para ellos. Con las herramientas que ofrece el programa resulta fácil recorrer las calles de cualquier pueblo, capturando las imágenes que más conmueven al participante por la carga emocional que posean para él los lugares representados en ellas. La posibilidad de movimiento a $360^{\circ}$ permite elegir el encuadre perfecto. La sesión se cerraría con una puesta en común de la experiencia en la que los participantes compartirían los sentimientos que han surgido en el curso del viaje de cada uno: añoranza, alegría, extrañeza, etc.

Durante la segunda sesión, cada uno de los participantes construiría una narrativa visual, creando una secuencia con las imágenes conseguidas en la fase anterior. Para este fin se usaría el programa de edición del vídeo KDENLIVE. Elegimos este software gratuito de libre código porque tiene un interfaz bastante intuitivo y ofrece todas las herramientas necesarias para crear un diaporama con un tiempo fijo o variable para cada imagen de la secuencia. Se proporcionaría a cada miembro del grupo una hoja explicativa con la lista de los comandos necesarios para realizar esta tarea. Sería importante incidir en que el relato visual obtenido tenga coherencia para el participante, conformando parte de su historia personal. Asimismo, la secuencia serviría de apoyo para la presentación que se realice en la última sesión, en la cual cada participante tendría oportunidad de compartir con los compañeros su álbum de "recuerdos prestados". Con este fin, sería conveniente que los participantes escriban y/o graben sus relatos personales para dar sentido a las imágenes recopiladas e incorporarlo como pista de audio para el diaporama creado. Como el dispositivo-grabadora se podría usar un teléfono móvil. Sin embargo, si por circunstancias (por falta del tiempo o por las dificultades lingüísticas, por ejemplo) no fuera posible, también se contemplaría la posibilidad de improvisar la narrativa durante el visionado posterior.

Por consiguiente, la última sesión se dedicaría a la puesta en común de los resultados obtenidos y la reflexión sobre la actividad en sí y la experiencia del desplazamiento migratorio de cada uno de los miembros del grupo. 
La presentación se haría proyectando la secuencia de imágenes creada por cada uno de los participantes, acompañada de un relato personal incorporado como pista de audio para el diaporama o verbalizado en el momento de la muestra por ellos mismos. Seguidamente, se propondría un debate sobre el desarrollo de la experiencia y su significado para cada uno de los presentes. Esta fase daría la oportunidad de compartir el duelo del desarraigo y sentir el reconocimiento y la aceptación de los demás. Aquí nos apoyamos en la afirmación de Lockett (2014): "El clima afectivo del momento de la narración, agrega la validación de la experiencia y de las emociones que se producen en el sujeto y puede ser reparador" (Lockett, 2014, p. 233).

Asimismo, la cuestión del lenguaje se torna crucial al entrar en el campo de la autodefinición narrativa, ya que la identidad según la teoría de Ricoeur (1996) se construye por medio de la autonarración continua, lo que implica expresar los significados usando construcciones cognitivas características para uno o varios idiomas. Por tanto, durante la presentación se permitiría que los participantes se expresen en su idioma natal, si lo consideran conveniente y luego los animaríamos a intentar explicar su historia en castellano para intentar conectar los dos relatos.

Hay que tener en cuenta que la actividad propuesta daría oportunidad de reconectar con los orígenes de los participantes a través de las fotografías ofrecidas por GOOGLE STREET VIEW. Sin embargo, el vínculo que se crearía de esta manera es frágil, ya que dependería de la presencia de las similitudes entre la imagen guardada en la memoria y la que aparece en la aplicación informática. Por consiguiente, podría romperse debido a las incongruencias temporales de los "recuerdos prestados". GOOGLE STREET VIEW incorpora las fotografías captadas a menudo mucho después de la partida del inmigrante de su tierra natal y actualiza sus registros continuamente. El paisaje se transforma con el tiempo, igual que la identidad de las personas se modifica bajo la influencia del entorno. La experiencia de ver estos pequeños cambios que acontecen en ausencia de uno puede resultar dolorosa y provocar el sentimiento de la frustración y la impotencia en el inmigrante. Aquí entra en escena la naturaleza discursiva y narrativa de la identidad construida en el contacto con el exterior. Mientras narramos nuestra historia, esta no para de cambiar y se hace necesaria su constante reinterpretación. Por consiguiente, consideramos importante, proponer una reflexión sobre este tema durante el desarrollo de la actividad, preferiblemente en la última sesión, para hacer frente a las posibles decepciones relacionadas con esta parte de la experiencia. El objetivo sería tratar que los participantes asuman que el cambio que se observa en el paisaje no supone una pérdida, sino una parte natural de la evolución del lugar, al igual que las transformaciones interiores que acontecen como el resultado del proceso de aculturación forman parte del crecimiento personal y no representan una traición a los orígenes de uno.

Finalmente, tras el taller se propondría a los participantes la oportunidad de exponer sus obras audiovisuales en un evento público y, de esta forma, poner en valor su trabajo y dar continuidad al proceso de intercambio cultural posibilitando la construcción de nuevos lazos con su entorno cultural actual. Para que las obras no presenten ningún problema en cuanto a derechos de autor, es importante que las imágenes recopiladas conserven la atribución de las mismas a GOOGLE, o sea conservar los elementos gráficos originales que incorpora la fotografía y cuidar que las inscripciones sean legibles.

Es importante mencionar que el alcance geográfico del registro visual del programa GOOGLE STREET VIEW tiene ciertas limitaciones. Por ejemplo, algunas países de África (como Sudán, Chad, Libia, Argelia, Marruecos, entre otros), Asia (China, Irak, Afganistán, etc.) no permiten acceso de los automóviles GOOGLE. Sin embargo, la compañía está negociando con sus gobiernos y algunos han cedido dejando la posibilidad que ciertas imágenes tomadas por los habitantes locales se incorporen al repositorio de la plataforma. Por consiguiente, cada vez más rincones del mundo aparecen reflejados en el mapa visual de GOOGLE. No obstante, mientras existen lugares sin registrar, deberíamos tener esta cuestión en cuenta a la hora de componer el grupo de los participantes del taller. Para no excluir a nadie, es importante pensar en posibles alternativas al uso de las imágenes del programa. En este sentido, podemos proponer realizar una búsqueda online de fotografías libres de 
Un álbum de recuerdos prestados: La fotografia de Google Street View como vestigio de pertenencia en la experiencia del desplazamiento migratorio

derechos o incorporar el material del archivo familiar. Por otro lado, esperemos que pronto las limitaciones de la plataforma que condicionan nuestro taller se superen, dada la dinámica positiva del desarrollo de las negociaciones en actualidad.

\section{Conclusiones}

En base al estudio bibliográfico realizado podemos concluir que la memoria personal se presenta como un punto de anclaje para la construcción de la identidad de un inmigrante. Una transformación profunda afecta a su "yo" como consecuencia del proceso de aculturación. Sus recuerdos y, sobre todo, la narrativa que se construye alrededor de ellos le permiten mantener la sensación de la estabilidad de su identidad. En este sentido, los paisajes de su pasado constituyen una referencia fundamental para su autodefinición, ya que son escenarios de acontecimientos importantes de su vida y también vestigios de la memoria colectiva y de la cultura de su comunidad nativa.

Hemos observado que el acto de rememorar el lugar de origen a través del paisaje fotográfico puede favorecer el proceso de la integración del inmigrante, ya que permite restablecer la continuidad de su relato personal, interrumpido por la experiencia de desplazamiento. Así, el sujeto tiene la oportunidad de reestructurar su narrativa identitaria y, al mismo tiempo, construir nuevos lazos de arraigo con el entorno de acogida. En este sentido, la plataforma GOOGLE STREET VIEW puede servir como herramienta para la mediación artística que permite realizar un viaje virtual al país natal del inmigrante y, así, recopilar las fotografías para su "álbum de recuerdos prestados". En el presente estudio hemos definido un planteamiento del taller que explora las posibilidades y las limitaciones de la metodología de la mediación a través de la fotografía de GOOGLE STREET VIEW, proponiendo un nuevo uso para esta aplicación informática. El objetivo de la actividad es poner en valor el pasado de los participantes, haciéndolos contar su historia a través de las imágenes. Asimismo, se pretende conectar sus recuerdos con su presente animándolos a exponer su relato ante los compañeros del taller, a compartir sus vivencias y a reflexionar sobre ellas. De esta manera, a través del proceso creativo de una obra fotográfica se abren nuevos horizontes en el proceso de la inclusión social y el crecimiento personal de los inmigrantes. Todas estas cuestiones no han podido ponerse a prueba todavía, pero estamos trabajando para poder realizar este taller en breve y completar nuestra investigación.

\section{Referencias}

CUELLAR, M. (2012). “La cruda y poética realidad está en Google. El artista Jon Rafman selecciona miles de imágenes de Google Street View y las convierte en su proyecto artístico" en El País, 22 de noviembre. $<$ http://cultura.elpais.com/cultura/2010/11/22/actualidad/1290380405_850215.html > [Consulta: 20 de noviembre de 2016]

GIMENEZ, G. (2001). “Cultura, territorio y migraciones. Aproximaciones teóricas”en Alteridades, vol. 11, issue 22 , p. 5-14.

KATZ, L. (2012). “Street Ghosts» posts Street View specters in real life”en CNET. $<$ https://www.cnet.com/news/street-ghosts-posts-street-view-specters-in-real-life/> [Consulta: 20 de mayo de 2017]

LATHROP, A. (2013). "La imagen sospechosa. Los nueve ojos de Google Street View" en Arte y crítica, n. 6 : Adictos a la realidad en la escena local, agosto. <http://www.arteycritica.org/ensayos/la-imagensospechosa-los-nueve-ojos-de-google-street-view/> [Consulta: 7 de noviembre de 2016]

LOCKETT, M. D. (2014). "Proyecto Enfocadas: «una experiencia grupal realizada con mujeres que sufrieron en el pasado violencia por parte de sus parejas, utilizando la fotografía y la narración como herramienta 
terapéutica»" en Arteterapia. Papeles de arteterapia y educación artística para la inclusión social, vol. 9, p. 225-246. <http://dx.doi.org/10.5209/rev_ARTE.2014.v9.47493> [Consulta: 3 de marzo de 2017]

MELERO, L. V. (coord.). (2010). La persona más allá de la migración. Manual de intervención psicosocial con personas migrantes. Valencia: Fundación CeiMigra.

MORENO, A. G. (2010). "La mediación artística: un modelo de educación artística para la intervención social a través del arte" en Revista Iberoamericana de Educación, vol. 52, n. 2, p.1-9.

MUÑOZ, M. M. y CRESPO, M. T. S. (2014). "Arteterapia y migración: inclusión social a través de la apropiación simbólica del paisaje" en Arteterapia. Papeles de arteterapia y educación artística para la inclusión social, vol. 9, n. 0, p. 13-24. <https://doi.org/10.5209/rev_ARTE.2014.v9.47479> [Consulta: 3 de marzo de 2017]

NOGUE, J. (2015). “Emoción, lugar y paisaje”. En Luna, T. y Valverde, I. (dir.). Teoría y paisaje II: Paisaje y emoción. El resurgir de las geografias emocionales. Barcelona: Observatorio del Paisaje de Cataluña; Universidat Pompeu Fabra. (pp.137-147).

RAFMAN, J. (2009). "IMG MGMT: The Nine Eyes of Google Street View" en Art F City, 12 de agosto. $<$ http://artfcity.com/2009/08/12/img-mgmt-the-nine-eyes-of-google-street-view/> [Consulta: 3 de abril de 2017]

REVILLA, J. C. (2003). "Los anclajes de la identidad personal" en Athenea Digital. Revista de Pensamiento e Investigación Social, n. 4, p. 54-67. <http://www.redalyc.org/articulo.oa?id=53700404> [Consulta: 3 de abril de 2017]

RICOEUR, P. (1996). Si mismo como otro. Madrid: Siglo XXI.

SLATER, D. (1997). "La fotografía doméstica y la cultura digital". En Lister, M. (1997). La imagen fotográfica en la cultura digital. Barcelona: Ediciones Paidós Ibérica, S.A. (pp. 173-195).

VALERA, S. (1997). "Estudio de la relación entre el espacio simbólico urbano y los procesos de identidad social" en Revista de Psicología Social, vol. 12, n. 1, p. 17-30. doi:10.1174/021347497320892009.

WALKER, T. (2012). "Google Street View photographs: the man on the street" en The Independent, 25 de julio. $<\mathrm{http} / /$ www.independent.co.uk/arts-entertainment/art/features/google-street-view-photographs-the-manon-the-street-7973255.html> [Consulta: 3 de marzo de 2017]

YANES, V. C. (2007). "La narrativa visual como metodología del sentido: articulación metodológica e implicaciones terapéutico-educativas"en Arteterapia. Papeles de arteterapia y educación artística para la inclusión social, vol. 2, p. 233-246. <https://doi.org/10.5209/rev_ARTE.2007.v2.9829> [Consulta: 23 de marzo de 2017]

ZAPIAIN, M. T. A. (2011). "Reflexiones identitarias en el territorio contemporáneo. La construcción colectiva de lugar. Caso de estudio de la Vega de Granada" en Biblia, vol. 48, p. 79-108. 